\title{
Evaluation of instructional software: Design considerations and recommendations
}

\author{
NANCY C. DUNCAN \\ Hampton University, Hampton, Virginia
}

\begin{abstract}
The elements of desirable research design for the evaluation of educational technology are discussed with reference to the context of existing research. Sources of internal invalidity, type of compared educational activity, and outcome measures are considered. Finally, recommendations regarding the direction of evaluation research are made. Research designs that take into account the characteristics of the learner, the software, and the teacher preferably within the framework of a model of the learning process should be adopted.
\end{abstract}

In the past 5-7 years, the use of educational software in psychology has flourished. Commercial software is now available for a variety of purposes, including computerassisted instruction (CAI), data generation for experiment simulation, conducting student-generated experiments, and data analysis. CAI software of some type is even included as part of the support package for introductory psychology texts with the purpose of influencing the decisions of faculty who have incorporated the computer into their professional activities. Yet, within the field of psychology, the experimental analysis of the efficacy of this software has received little attention. The introduction of hypermedia has brought additional issues such as the type of presentation (text, graphics, sound, video) and the optimal degree of the learner's control, to the foreground. Research designs to assess the multivariate nature of the learning process are needed.

This paper includes both a discussion of the evaluation of software, which is supported by personal experiences in assessing the role and efficacy of computers in learning, and a review of the literature. There are studies from a variety of academic disciplines and populations with implications for the evaluation of courseware for psychology. Problems with research design discovered in the review of this literature ranged from violations of the most basic principles of good design to questions regarding the most productive research approach.

\section{Research Design Considerations: Internal Validity}

There are several possible sources of invalidity in the research on the efficacy of software. There are practical limitations to evaluative research. One problem associated with the use of between-group designs, for example, is the possibility of selection bias due to the nonrandom assignment of subjects. This possibility increases when different experimental treatments are applied to different sections of a course (or to different classes in primary and sec-

Correspondence should be addressed to N. C. Duncan, Department of Psychology, Hampton University, Hampton, VA 23668. ondary school). The members of one (or more) section of a course receive CAI while the remaining section or sections serve as no-treatment or other controls. Personal experience in teaching multiple sections of courses suggests that class performance, interest in the subject, and related variables can vary significantly in the absence of differential treatment, even when class size is fairly large (35-50 students) and when a class comprises either those majoring in psychology or a mixture of disciplines. Such designs (Sawyer, 1988; also cited in Shlechter, 1988) may be confounded by differences in students' characteristics.

The random assignment of subjects to experimental conditions has been incorporated in much of the research on the efficacy of software (Hannafin \& Carney, 1991; Schloss, Sindelar, Cartwright, \& Schloss, 1986; Schloss, Wisniewski, \& Cartwright, 1988; Thomas \& Bostow, 1991), but the possibility of subjects' bias remains. Some researchers have taken measures of subject variables considered relevant to check for possible differences between the groups of subjects in an experiment. For example, Trowbridge (1987), in a study on the effects of working in groups at the computer, obtained measures of age, sex, grade-point average, and family income. Liefeld and Herrmann (1990) selected other variables for analysis: academic major, number of previous courses in the major, an English aptitude test, semester grade average, and other variables selected to ensure academic equivalence among the groups. Unfortunately, measurement of learners' characteristics is an exception in evaluation research.

If matching to control for learner characteristics is attempted as in Underwood and Underwood (1987) and Varnhagen and Zumbo (1990), the question is which of the students' characteristics should be assessed (measures of ability, aptitude, or motivation; prior knowledge of the subject; etc.) and what instruments should be used for such assessments. There is little consistency in the literature. The choice of outcome measures partly determines the variables selected for matching, and these measures may vary considerably from one investigation to another. Underwood and Underwood (1987) matched subjects on reading ability because it had been demonstrated that this 
variable was positively associated with classificatory skills, one of the dependent variables. Subjects were also matched on IQ scores and in a pretest classification task.

Some (see Tobias, 1987) have argued that prior knowledge in a particular area is a powerful predictor of subsequent performance and hence an important potential source of subjects' bias. Computer anxiety (Lambert \& Lenthall, 1989) or more generalized anxiety (Tobias, 1987) may also be relevant subject variables. Obtaining information from subjects for the purposes of matching substantially increases the time and effort required for completion of the investigation. Perhaps this accounts for the lack of popularity of matched-subject designs in the evaluation literature.

Tobias (1987) reviewed aptitude treatment interactions (ATI) research, in which the relationship between the characteristics of learners and instructional outcomes is examined. In ATI research the assumption is made that the optimal instructional method varies as a function of students' characteristics. ATI research has produced inconclusive results. Alterations in content to be learned or instructional methods has substantially changed or eliminated the interactions, perhaps because different instructional procedures or course contents invoke different types of cognitive processing. Recently, the focus has turned to understanding the cognitive processes underlying learners' abilities (e.g., spatial or reading ability), as well as other processes, including working memory (Hunt, 1985).

Between-group educational research is also subject to a lack of consistency of instruction across sections of a course. Even when the same faculty member conducts all sections, class questions and discussions can alter the progress of a lecture. When different faculty are responsible for different sections, the effectiveness of computerbased instruction (CBI), as measured by a meta-analysis, has been found to be significantly greater (C. L. C. Kulik \& J. A. Kulik, 1991). However, the variables (such as the teacher's enthusiasm, dedication, and openness to new teaching methods) responsible for these results have yet to be systematically investigated (Shlecter, 1988).

Another set of threats to internal validity arise from the awareness of students that some are receiving CAI while others are not. Resentful demoralization and/or compensatory rivalry (Neale \& Liebert, 1986) are possible but could be assessed. In smaller institutions, and perhaps in larger universities as well, students in a department regularly compare class experiences and would quickly become aware of different teaching methods. The specter of insistent requests for equal treatment has limited some, including myself, from instituting between-subject designs in small institutions. A related ethical question is the problem of justifying denying some students the benefits of $\mathrm{CAI}$ or other computer learning experiences if the computer component is tied to course performance and therefore the course grade.

Within-group designs in which CAI is implemented in one or more parts of the course and performance is compared with that in other segments not supplemented or taught with CAI also have a number of problems. Fore- most is the difficulty of equating the subject matter and performance measures over different parts of the course. In a class on abnormal psychology, Lambert and Lenthall (1989) used a pre-, posttest design to assess the effects of case simulations on computer anxiety. Duncan (1991) attempted to resolve some of these difficulties through the use of CAI in the second of four components of her research design course. Some investigators (Tobias, 1987) have indicated that acquisition of concepts in different sections of the same course may require the utilization of different cognitive strategies or be most compatible with particular cognitive styles. If so, within-group designs would not be appropriate for efficacy studies. Instead, between-group designs with the same course content would be a better choice. Within-group designs, on the other hand, do have the advantages of increased power, as well as control for differences among subjects.

\section{Independent Variables and Type of Compared Educational Activity}

Another design feature to be considered is the type of compared educational activity. Since some studies (Grabe, Petros, \& Sawler, 1989; Petty \& Rosen, 1990) use only a no-treatment control group, the possibility exists that other instructional activities not requiring the use of computers would produce similar or even larger gains in performance. In other cases, because of the difficulty of equating different educational treatments, more than one factor is permitted to vary. For example, Thomas and Bostow (1991) found no significant differences in posttest scores between groups to whom rational-emotive therapy concepts were presented in either 300 written statements with key concepts replaced by blanks requiring the students to fill in an accompanying answer sheet or the same 300 statements on a computer screen. Feedback (whether the typed answer was correct or incorrect) was also present in the computer-based condition. However, only the CAI group performed significantly better than they did on the pretest, in comparison with controls who did not actively participate while completing the assigned reading. Although this experiment is one of the few in which an attempt has been made to systematically compare techniques, the fact that a confound exists makes it difficult to draw definite conclusions.

The selection of a proper activity for comparison is difficult, for two reasons: (1) The complexity of educational software makes it difficult for researchers to specify the essential characteristics of the educational activity it provides; the independent variable is thus not clearly defined. (2) As Reeves (1986) points out, the differences and commonalities between new and traditional (e.g., lectures) types of instruction are often ignored or not understood.

\section{The Role of Naturalistic Observation}

From using different types of CAI over the past 3 years in several courses, it has become clear to me that many students approach the prospect of using the computer lab with little enthusiasm. Supplemental exercises or computerbased experiments are seen by some not as an educational 
opportunity, but rather as an added requirement that encroaches upon an already busy schedule. It is not uncommon for a significant percentage of students to come to the lab without reading the assigned text material, to fail to read the lab handouts, and to seek to obtain the correct answers from the lab staff instead of completing the work themselves. Data are sometimes collected for computerbased experiments with seemingly little regard for accuracy or professionalism. If the behavior of students who are using educational software affects experimental outcomes, such behavior should be the subject of research. Neuman (1991) conducted a naturalistic observation of learning-disabled students' (ages 9-18) interactions with 26 software packages. This comprehensive 2 -year investigation focused on the difficulties encountered by mildly handicapped students in working with software packages. Her assumption was that this population would have problems of degree rather than type in comparison with nonhandicapped peers, and that the results of such research would provide insights about CAI. Some of the problems identified were reading difficulties, lack of motivating appeal of the program, software that did not clearly explain the reason for errors, and response requirements that allowed the student to advance through the program without understanding the material. Grabe et al. (1989) found that college students voluntarily using CAI in an educational psychology course had significantly higher reading scores than did their classmates. The problem of inadequate reading skills has implications for the design and use of educational software, especially in the light of decreasing SAT scores for entering college freshmen.

Naturalistic observations could also be used for formative evaluation of software.

\section{Outcome Variables}

Another critical component of a good research design is the selection and measurement of outcome variables. The choice of the optimal dependent variable or variables to be used in the evaluation of educational technology is a subject of much debate. Baker and O'Neil (1987) have described the history and rationale of two approaches for measuring educational outcomes: (1) criterion-referenced measurement (CRM), a process of selecting a well-defined behavior domain as a means of determining achievement; and (2) norm-referenced tests, in which performance is measured in comparison with other scores in a particular distribution. The use of CRM requires the generation of a set of test items (the test could consist of either paperand-pencil or behavioral tasks, to measure skills) from a universe of content and behavior called a domain. Controversy developed over the correct method of obtaining the items, the details of which will not be discussed here. The point is that test construction theory is relevant to the issue of evaluation, but that it is typically not even considered by psychologists who are interested in the evaluation of instructional technology.

One strategy for evaluating the efficacy of software has been the use of multiple-choice tests covering program content to measure performance (Duncan, 1991; Petty \&
Rosen, 1990; Welsh \& Null, 1991). Test items are chosen from textbook test banks or generated by the investigators. Usually neither set of questions has been examined for reliability or more than face validity. The quality of software evaluation, both formative and summative, could benefit from collaborative work among researchers with expertise in test construction and programming skills.

Outcome measures are necessarily a function of the goals of the software's developers and users. Although test performance is a reasonable measure of acquired information, the performance assessment structure of most college courses makes the use of this measure alone inadequate. Hannafin and Carney (1991) conducted an investigation into the effect of review strategies that were designed to influence students' cognitive processing of the content of an instructional software package. The lesson consisted of a summary of the geography, history, and culture of a fictional South Sea island in which a "new" ore had been discovered. The effects of behavioral strategies emphasizing recall of information presented in each section were compared with the effects of cognitive review strategies designed to promote meaningful integration with existing schemata. No differences were found in the college students' performance on a 24-item, short-answer test that contained both factual and inferential questions. There were differences, however, in the other dependent variables: (1) The total number of words used in answers, a measure of the quality of the response, was significantly greater in the cognitive condition; (2) the number of personal elaborations, a measure of far-transfer of information, was also greater in the cognitive condition; and (3) the behavioral strategy resulted in significantly more ideas related to the specific content of the program (a neartransfer measure). This study makes a dual contribution to the issue of evaluation by focusing on the use of different cognitive instructional strategies and by broadening the type of dependent measure utilized.

There are, of course, other outcome measures of interest. It is important to understand the effect of CAI on students' attitudes toward computer-based learning and toward the particular software packages employed. A number of studies (Cordell, 1991; Duncan, 1991; Goolkasian, 1989; Lambert \& Lenthall, 1989) have included this outcome measure, and several scales (Heinssen, Glass, \& Knight, 1987; Meier, 1988; Simonson, Maurer, Montag-Torardi, \& Whitaker, 1987) have been developed to facilitate this process. Most have reported positive attitudes, although Cordell did not include a complete summary of her feedback questionnaire. It is to be hoped that other researchers will include a similar posttest to assess students' perceptions of the usefulness of the program, its match with their preferred learning styles, and any problems that they encountered. In fact, students' attitudes toward the instructional method may mediate other variables (perceived learning and preparedness) that influence performance (Varnhagen \& Zumbo, 1990).

The merits of educational software cannot be fully assessed without one's determining its effect on other outcome measures. One critical variable is the degree to 
which educational software stimulates interest in course content, career choice, and so forth. Much software has been developed for education in experimental psychology. Data generators, programs that permit the student to conduct experiments, user-friendly statistical packages, and CAI for statistics courses (see, e.g., Varnhagen \& Zumbo, 1990) are among the most common packages. The unanswered question is whether the use of these instructional tools stimulate student interest in psychology as a science. Since the use of experiment simulators and generators is popular, data on such long-term factors as the number of students reporting an increased interest in research, participating in research projects, and choosing research careers after exposure to experimental design software could be collected.

\section{Directions for Research}

Until now, most research on the efficacy of educational software has been experimental or quasiexperimental. Much, as discussed above, has contained flaws in design. The principles of good research design (as that in Neale \& Liebert, 1986) should therefore be followed. In addition, certain outcome measures deserve further investigation, the foremost of which are the performance measures used to determine learning and, consequently, grades. Although the results of metaanalysis indicate a modest increase in exam scores (Niemiec \& Walberg, 1987; C. L. C. Kulik \& J. A. Kulik, 1991), the studies from which these results were drawn contain relatively few on the effectiveness of computer software in college psychology courses.

One of the mostly untapped capabilities of the computer is its use to simultaneously provide a learning environment and assess the nature of the learning process. Several packages have been written that offer this potential. Ransdell (1990) has developed software to study the writing process. Real-time replay captures writers' keystrokes and replays them in real time. Ray and Mitchell (1992) have developed BehSys Anal, a HyperCard-based resource library with the capability of recording the user's search strategies and choices. The authors plan to obtain a large database and examine variables such as feedback, self-pacing, associative paths, and so forth. Another program is still in development by Levidow, Hunt, and McKee (1991). Called the DIAGNOSER, it will both help instructors develop tutorials and collect data for instructional enhancement and theoretical investigations into the learning process. The collected data can be used for a variety of purposes, including the assessment of daily student progress and the tailoring of lectures or other learning activities to the students' knowledge.

Experimental studies in which computer-based learning is compared with other instructional techniques may be the least productive method of investigation. Reeves (1986) has argued that even when experimental designs are properly conducted, they are of limited usefulness in educational research. Although the results of metaanalysis (C. L. C. Kulik \& J. A. Kulik, 1991; J. A. Kulik \& C. L. C. Kulik, 1987; McNeil \& Nelson, 1991; Niemiec
\& Walberg, 1987) indicate a moderate positive effect of the use of computers in the educational process, the critical causal factors remain unknown. Designs that emphasize obtaining statistical significance, therefore, do not provide guidelines for future software development or use.

A number of alternative approaches exist. One is the use of multivariate correlational designs (Cooley \& Lohnes, 1976; Reeves, 1986), which have a number of advantages for applied research situations: (1) These designs can be used to assess the amount of student achievement variance produced by predictor variables, and (2) they allow for the assessment of multiple predictor variables, such as students' characteristics, features of the software, and the context of instruction.

Causal models of the effects of instructional software on the learning process are needed. Several causal models of the influence of instructional treatments on outcomes have been developed (see Borich \& Jamelka, 1982; Cooley \& Lohnes, 1976; Leinhardt, 1980; Reeves, 1986); these have the potential to direct research efforts in a more fruitful direction. Finally, the incorporation of knowledge from cognitive psychology will assist in the building of these causal models.

\section{Status of Software Evaluation in Psychology}

In spite of the fact that most psychologists are trained in research methods, there has been no rush to conduct rigorous empirical studies of efficacy. New software or computer-based teaching systems are regularly introduced in Behavior Research Methods, Instruments, \& Computers without the requirement of even the simplest measures of efficacy (see, e.g., Bradley, 1989; Bradley, Hemstreet, \& Ziegenhagen, 1992; Chute, 1986; Conn, Stafiniak, DiPasquale, \& Harper, 1988; Dougherty, 1990; Isaacs, Costenbader, Reading-Brown, \& Goodman, 1992; Perone, 1991; Ransdell, 1992; Ransdell \& Levy, 1989; St. James, 1989; Schneider, 1988). There are, of course, substantive reasons for not conducting evaluation research. As Baker and O'Neill (1987) observe, evaluation can have a strong negative impact. Exploratory development and risk taking (both in time invested and financial resources) can be inhibited. Failure to demonstrate the efficacy of CAI would make it more difficult to generate funding for computer labs and educational instruction. Nevertheless, software, or any other instructional tool, must be evaluated. Good intentions and hard work are not sufficient justification for its use.

\section{REFERENCES}

BAKER, E. L., \& O'NeIL, H. F., JR. (1987). Assessing instructional outcomes. In R. Gagne, (Ed.), Instructional technology: Foundations (pp. 343-377). Hillsdale, NJ: Erlbaum.

Borich, G. D., \& JemelKa, R. P. (1982). Programs and systems: An evaluation perspective. New York: Academic Press.

Bradley, D. R. (1989). Computer simulation with DATASIM. Behavior Research Methods, Instruments, \& Computers, 21, 99-112.

Bradley, D. R., Hemstreet, R. L., \& Ziegenhagen, S. T. (1992). A simulation laboratory for statistics. Behavior Research Methods, Instruments, \& Computers, 24, 190-204. 
Chute, D. L. (1986). MacLaboratory for psychology: General experimental psychology with Apple's Macintosh. Behavior Research Methods, Instruments, \& Computers, 18, 205-209.

Conn, G., Stafiniak, P., DiPasquale, M. C. \& Harper, L. (1988). Effects of teaching an introductory psychology laboratory using a computerized research tool. Behavior Research Methods, Instruments, \& Computers, 20, 184-187.

COOley, W. W., LoHNEs, P. R. (1976). Evaluation research in education. New York: Irvington.

CORDELL, B. J. (1991). A study of learning styles and computer-assisted instruction. Computers \& Education, 16, 175-183.

DougherTy, T. J. (1990). Contour: A hypermedia environment for teaching about subjective contours and other visual illusions. Behavior Research Methods, Instruments, \& Computers, 22, 223-227.

DUNCAN, N. C. (1991). CAI-enhanced exam performance in a research design course. Behavior Research Methods, Instruments, \& Computers, 23, 324-327.

Goolkasian, P. (1989). Computerized laboratories for psychology instruction: How successful are they? Behavior Research Methods, Instruments, \& Computers, 21, 148-150.

Grabe, M., Petros, T., \& Sawler, B. (1989). An evaluation of computer assisted study in controlled and free access settings. Jourmal of Computer Based Instruction, 16, 110-116.

Hannafin, M. J., \& Carney, B. W. (1991). Effects of elaboration strategies on learning and depth of processing during computer-based instruction. Journal of Computer-Based Instruction, 18, 77-82.

Heinessen, R. K., Glass, C. R., \& Knight, L. A. (1987). Assessing computer anxiety: Development and validation of the Computer Anxiety Rating Scale. Computers in Human Behavior, 3, 49-59.

HUNT, E. (1985). Verbal ability. In R. Stemberg (Ed.), Human abilities: An information-processing approach (pp. 99-123). New York: W. H. Freeman.

Isaacs, M., Costenbader, V., Reading-Brown, M., \& Goodman, G. (1992). Using a computer simulation in the research, training, and evaluation of school psychologists. Behavior Research Methods, Instruments, \& Computers, 24, 165-168.

KuLIK, C. L. C., \&ULIK, J. A. (1991). Effectiveness of computerbased instruction: An updated analysis. Computers in Human Behavior, 7, 75-94.

Kulik, J. A., \& Kulik, C. L. C. (1987). Review of recent research literature on computer-based instruction. Contemporary Educational Psychology, 12, 222-230.

LAMBERT, M. E., LENTHALL, G. (1989). Effects of psychology courseware use on computer anxiety in students. Computers in Human Behavior, 5, 207-214.

LEINHARDT, G. (1980). Modeling and measuring educational treatment in evaluation. Review of Educational Research, 50, 393-420.

Levidow, B. B., Hunt, E., \& MCKeE, C. (1991). The DIAGNOSER: A HyperCard tool for building theoretically based tutorials. Behavior Research Methods, Instruments, \& Computers, 23, 249-252.

Liffeld, J. P., \& HeRrmanN, T. F. (1990). Learning consequences for University students using computerized mastery testing. Educational Technology, Research \& Development, 38, 19-25.

MCNeIL, B. J., \& NeLson, K. R. (1991). Meta-analysis of interactive video instruction: A 10 year review of achievement effects. Journal of Computer-Based Instruction, 18, 1-6.

MEIER, S. T. (1988). Predicting individual differences in performance on computer-administered tests and tasks: Development of the Conputer Aversion Scale. Computers in Human Behavior, 4, 175-187.

NeALE, J. M., \& LIEBERT, R. M. (1986). Science and behavior: An introduction to methods of research (3rd ed.). Englewood Cliffs, NJ: Prentice-Hall.

Neuman, D. (1991). Learning disabled students' interactions with commercial courseware: A naturalistic study. Educational Technology, Research \& Development, 39, 31-49.

Niemiec, R., \& Walberg, H. J. (1987). Comparative effects of computer-assisted instruction: A synthesis of reviews. Journal of Educational Computing Research, 3, 19-37.
Perone, M. (1991). Computer-based methodology laboratories: 1. An undergraduate course in experimental psychology. Behavior Research Methods, Instruments, \& Computers, 23, 121-126.

Petty, L. C. , Rosen, E. F. (1990). Increase in mastery levels using a computer-based tutorial/simulation in experimental psychology. Behavior Research Methods, Instruments, \& Computers, 22, 216218.

RANSDELL, S. E. (1990). Using a real-time replay of students' word processing to understand and promote better writing. Behavior Research Methods, Instruments, \& Computers, 22, 142-144.

RANSDELL, S. [E.] (1992). Incorporating educational software into large introductory psychology lectures and labs. Behavior Research Methods, Instruments, \& Computers, 24, 172-173.

RANSDELL, S. [E.], LeVy, C. M. (1989). A flexible and interactive software package for a laboratory in cognition and perception. Behavior Research Methods, Instruments, \& Computers, 21, 160162.

RAY, R. D., Mitchell, N. (1992). BehSys Anal: An artificially intelligent hypermedia resource library for descriptive behavioral research. Behavior Research Methods, Instruments, \& Computers, 24, 180-189.

REEVES, T. C. (1986). Research and evaluation models for the study of interactive video. Journal of Computer-Based Instruction, 13, $102-106$

ST. JAMES, J. D. (1989). The MEL Library in the undergraduate research methods course. Behavior Research Methods, Instruments, \& Computers, 21, 245-247.

SAWYER, T. A. (1988). The effects of computerized and conventional study guides on achievement in college students. Joumal of ComputerBased Instruction, 15, 80-82.

Schloss, P. J., Sindelar, P. T., Cartwright, G. P., \& Schloss, C. N. (1986). Efficacy of higher cognitive and factual questions in computer assisted instruction modules. Joumal of Computer-Based Instruction, 13, 75-80.

Schloss, P. J., Wisniewski, L. A., CARTwright, G. P. (1988). The differential effect of learner control and feedback in college students' performance on CAI modules. Journal of Educational Computing Research, 4, 141-150.

SCHNEIDER, W. (1988). Micro Experimental Laboratory: An integrated system for IBM PC compatibles. Behavior Research Methods, Instruments, \& Computers, 20, 206-217.

Shlechter, T. M. (1988). An examination of the research evidence for computer-based instruction. In H. R. Hartson \& D. Hix (Eds.), Advances in human-computer interaction (Vol. 2, pp. 316-367). Norwood, NJ: Ablex.

Simonson, M. R., Maurer, M., Montag-Torardi, M., \& WhitAKer, M. (1987). Development of a standardized test of computer literacy and a computer anxiety index. Joumal of Educarional Computing Research, 3, 231-247.

Thомаs, D. L. Bostow, D. E. (1991). Evaluation of pre-therapy computer-interactive instruction. Joumal of Computer-Based Instruction, 18, 66-70.

Tobias, S. (1987). Learner characteristics. In R. Gagne (Ed.), Instructional technology: Foundations (pp. 207-231). Hillsdale, NJ: Erlbaum.

TrowBridge, D. (1987). An investigation of groups working at the computer. In D. E. Berger, K. Pezdek, \& W. Banks (Eds.), Applications of cognitive psychology: Problem solving, education and computing (pp. 47-57). Hillsdale, NJ: Erlbaum.

UNDERWOOD, G., \& UNDERWOOD, J. D. M. (1987). The computer in education: A force for change? In F. Blackler \& D. Oborne, (Eds.), Information technology and people: Designing for the future (pp. 167. 190). Letchworth, U.K.: British Psychological Society.

Varnhagen, C. K., \& Zumbo, B. D. (1990). CAI as an adjunct to teaching introductory statistics: Affect mediates learning. Journal of Educational Computing Research, 6, 29-40.

WELSH, J. A., \& NULL, C. H. (1991). The effects of computer-based instruction on college students' comprehension of classic research. Behavior Research Methods, Instnuments, \& Computers, 23, 301-305. 